Public Reporting burden for this collection of in formation is cstimated to average 1 hour per response, including the time for revicwing instructions, searching existing data sources, gathering and maintaining the data necded, and completing and reviewing the collection of information. Send comment regarding this burden estimates or any other aspect of this collection of information, including suggestions for reducing this burden, to Washington Headquarters Services, Directorate for information Operations and Reports, 1215 Jefferson Davis Highway, Suite 1204, Arlington, VA 22202-4302, and to the Office of Management and Budget, Paperwork Reduction Project (0704-0188,) Washington, DC 20503.

\begin{tabular}{|l|l|l|l}
\hline 1. AGENCY USE ONLY ( Leave Blank) & $\begin{array}{l}\text { 2. REPORT DATE } \\
\text { July 10,2006 }\end{array}$ & $\begin{array}{l}\text { 3. REPORT TYPE AND DATES COVERED } \\
\text { Technical Report \#11 Jan 1, 2003-July 1, 2006 }\end{array}$ \\
\hline 4. TITLE AND SUBTITLE & \begin{tabular}{l} 
J FUNDING NUMBERS \\
\hline
\end{tabular}
\end{tabular}

Ceramics Contriming Layers Bocigned for Increased Resistanee to fregmentation Damage See Report 6. AUTHOR(S)

Frederick F. Lange, PI

7. PERFORMING ORGANIZATION NAME(S) AND ADDRESS(ES)

Materials Department

College of Engineering

5. FUNDING NUMBERS

N00014-03-1-0350

University of California

Santa Barbara, CA 93106-5050

9. SPONSORING / MONITORING AGENCY NAME(S) AND ADDRESS(ES)

Office of Naval Research

Ballston Centre Tower One

800 North Quincy Street

Arlington, VA 22217-5660

11. SUPPLEMENTARY NOTES

The views, opinions and/or findings contained in this report are those of the author(s) and should not be construed as an official Department of the Army position, policy or decision, unless so designated by other documentation.

12 a. DISTRIBUTION / AVAILABILITY STATEMENT
Approved for public release; distribution unlimited.

13. Abstract Ion Exchanged, Glass Laminates that Exhibit a Threshold Strength

Scott P. Fillery, Frederick F. Lange *

Materials Department, University of California, Santa Barbara, California 93106

Glass laminates, fabricated to contain periodic thin layers containing biaxial compressive stresses, exhibit a threshold strength, i.e., a stress below which failure will not occur. Ion exchange treatments in $\mathrm{KNO}_{3}$ at 350 to $450{ }^{\circ} \mathrm{C}$ for periods of 3 to 72 hrs were used to create residual compressive stresses at the surface of soda lime silicate glass sheets. Wafer direct bonding of the ion exchanged glass sheets resulted in glass laminates with thin layers of compressive stress adjacent to the glass interfaces. Critical strain energy release measurements of the bonded interface were used to optimize the bonding temperature/time to avoid significant relaxation of the stress produced by ion exchange. Stress profiles, determined via the wafer curvature measurement method, showed a residual stress maximum of $328 \mathrm{MPa}$ for an ion exchange temperature of $450^{\circ} \mathrm{C}$. The threshold flexural strength of the ion exchanged glass laminates was determined to be $112 \mathrm{MPa}$ after the introduction of indentation cracks with indent loads ranging from $1 \mathrm{~kg}$ to $5 \mathrm{~kg}$. Contrary to similar ceramic laminates, where cracks either propagate across the compressive layer or bifurcate within the compressive layer, the cracks in the glass laminates were deflected along the interface between the bonded sheets.

\begin{tabular}{|c|c|c|c|}
\hline \multicolumn{3}{|c|}{ 14. SUBJECT TERMS Glass Laminates, Threshold strength, ion exchange, wafer bonding } & \multirow{2}{*}{$\begin{array}{l}\text { 15. NUMBER OF PAGES } 20 \\
\text { 16. PRICE CODE }\end{array}$} \\
\hline & & & \\
\hline $\begin{array}{l}\text { 17. SECURITY CLASSIFICATION } \\
\text { OR REPORT } \\
\text { UNCLASSIFIED }\end{array}$ & $\begin{array}{l}\text { 18. SECURITY CLASSIFICATION } \\
\text { ON THIS PAGE } \\
\text { UNCLASSIFIED }\end{array}$ & $\begin{array}{l}\text { 19. SECURITY CLASSIFICATION } \\
\text { OF ABSTRACT } \\
\text { UNCLASSIFIED }\end{array}$ & $\begin{array}{l}\text { 20. LIMITATION OF ABSTRACT } \\
\text { UL }\end{array}$ \\
\hline
\end{tabular}

NSN 7540-01-280-5500 


\title{
Ion Exchanged, Glass Laminates that Exhibit a Threshold Strength
}

\author{
Scott P. Fillery, Frederick F. Lange * \\ Materials Department, University of California, Santa Barbara, California 93106
}

\begin{abstract}
Glass laminates, fabricated to contain periodic thin layers containing biaxial compressive stresses, exhibit a threshold strength, i.e., a stress below which failure will not occur. Ion exchange treatments in $\mathrm{KNO}_{3}$ at 350 to $450{ }^{\circ} \mathrm{C}$ for periods of 3 to $72 \mathrm{hrs}$ were used to create residual compressive stresses at the surface of soda lime silicate glass sheets. Wafer direct bonding of the ion exchanged glass sheets resulted in glass laminates with thin layers of compressive stress adjacent to the glass interfaces. Critical strain energy release measurements of the bonded interface were used to optimize the bonding temperature/time to avoid significant relaxation of the stress produced by ion exchange. Stress profiles, determined via the wafer curvature measurement method, showed a residual stress maximum of $328 \mathrm{MPa}$ for an ion exchange temperature of $450^{\circ} \mathrm{C}$. The threshold flexural strength of the ion exchanged glass laminates was determined to be $112 \mathrm{MPa}$ after the introduction of indentation cracks with indent loads ranging from $1 \mathrm{~kg}$ to $5 \mathrm{~kg}$. Contrary to similar ceramic laminates, where cracks either propagate across the compressive layer or bifurcate within the compressive layer, the cracks in the glass laminates were deflected along the interface between the bonded sheets.
\end{abstract}

\section{Introduction}

Because of the large variation in flaws, most of which are introduced during processing, the strength of ceramics are typically characterized using statistical distribution functions, such as those described by Weibull. ${ }^{1}$ For this reason, designing structures and components with ceramics is a challenge and proof testing each individual component becomes a necessary and expensive process to ensure reliability at high stresses.

Past research concerning the mechanical reliability ceramics emphasized microstructure modifications with a goal of increasing crack growth resistance. The incorporation of either fibers, or whiskers or a phase that undergoes a stress induced transformation results in what is known as a 'rising R-curve' behavior and an increasing resistance to crack extension. ${ }^{2,3}$

More recent studies have shown that thin, periodic compressive layers can 'trap' cracks greater than a given size, and because of the increasing load needed to extend the crack though the compressed material, these materials also have a 'rising R-curve' behavior. But, more * Member, American Ceramic Society All correspondence to flange $a$ enginecring.ucsb.edu Supported by the Office of Naval Research, US Department of Defense, under grant contract No. N00014-03-1-0350 
importantly, these laminates are not expected to fail below a given stress, known as the threshold strength. The threshold strength is known to depend on the space between the periodic compressive layers, the thickness of the compressive layer itself, the magnitude of the compressive stress, $\sigma_{c}$, the critical stress intensity factor for the compressive layer, $\mathrm{K}_{\mathrm{c}}$, the ratio of the elastic properties of the two materials ${ }^{4-7}$, and the volume fraction of the compressive layer material. In this way, a route has been found to truncate the strength statistics, and thus ensure a reliable component above a certain stress, namely, the threshold strength.

Glasses primarily fail from surface flaws. The strength of glasses has been increased by inducing a compressive stress at the surface by either ion exchange (exchanging smaller ions with larger ones) ${ }^{8}$ or tempering. If the depth of the compressive surface layer is sufficient to embed all surface cracks, the failure stress depends primarily on the magnitude of the compressive stress. In general, the stress vs depth profile is not a step function, nor does the compressive stress completely embed all surface cracks. Thus, although the compressive stress increases the strength, it does not produce a threshold strength.

The interest here is to use the ion exchange process to place periodic compressive layers within a glass laminate. Briefly, the process creates surface compressive stresses in glass plates that are subsequently bonded together without dissipating all of the compressive stress. Several glass bonding technologies are currently applied in different industries. These include fusion bonding, spin-on bonding, ${ }^{9}$ anodic bonding ${ }^{10}$ and wafer direct bonding. ${ }^{11,12}$ Each has been tailored to the specific requirements of a different industry and combined with the ion exchange technique, each suggests the possibility of creating a laminate structure containing periodic compressive stresses. The most attractive laminate construction method combines the well researched chemical strengthening technique of ion exchange with wafer direct bonding, a relatively new procedure primarily used in the semiconductor, Microelectromechanical-Systems (MEMS) and Micro Total Chemical Analysis System ( $\mu$-TAS) industries to bond silicon or $\mathrm{SiO}_{2}$ wafers together at low temperatures without damaging surface features. ${ }^{12}$ The viability of wafer direct bonding to glasses such as Pyrex has been demonstrated. ${ }^{13}$ In all cases wafer direct bonding has shown flexibility, allowing the bonding of glasses of identical and dissimilar compositions. Wafer direct bonding does however, exhibit certain limitations including strict tolerances on surface roughness and flatness, high sensitivity to interface contamination ${ }^{12}$ and previous practices have limited bonding to only 2 wafers.

Below, we describe the production and subsequent strength properties of a glass laminate, fabricated with plates of a soda lime silicate glass, where the surfaces were placed in compression via ion-exchange, and bonded together to produce a transparent laminate. The strength properties and fracture behavior are investigated to determine whether glass laminates consisting of thin, periodic compressive stress layers can demonstrate similar attributes to laminated ceramic composites of the same architecture, namely crack arrest and crack bifurcation within the stressed layers and most importantly a threshold strength.

\section{Experimental Procedure}

\section{Ion Exchange and Stress Determination}

Soda Lime Silicate glass slides (Corning Code 2947) with the dimensions of $75 \times 25 \times 1 \mathrm{~mm}$ were used in this work. The chemical composition of the glass slides, reported by the manufacturer, was $73 \% \mathrm{SiO}_{2}, 14 \% \mathrm{Na}_{2} \mathrm{O}, 7 \% \mathrm{CaO}, 4 \% \mathrm{MgO}, 2 \% \mathrm{Al}_{2} \mathrm{O}_{3}$. The as reccived glass 
slides were scribed and broken to the approximate dimensions $50 \times 25 \times 1 \mathrm{~mm}$. For those specimens to be tested as single ion exchanged sheets, the edges were beveled with 400 grit silicon carbide abrasive paper to remove edge flaws that could influence the mechanical tests. The glass was then annealed at $550^{\circ} \mathrm{C}$ for $8 \mathrm{hr}$ to remove any residual stress.

The ion exchange process was accomplished in a vertical clam-shell furnace with surrounding Fiberfrax High Temperature Insulation (Unifrax, Niagara Falls, NY) containing a stainless steel vessel. The temperature was controlled using a Programmable Controller (Fluke) connected to both a thermocouple surrounding the molten salt vessel and a thermocouple inserted into the molten salt. The glass plates were held in a titanium mesh basket as separated pieces, lowered into the furnace and held above the molten salt for $15 \mathrm{~min}$. before immersion. The glass slides were treated in molten potassium nitrate $\left(\mathrm{KNO}_{3}\right)$ at temperatures ranging from $350{ }^{\circ} \mathrm{C}$ to $450^{\circ} \mathrm{C}$ and periods ranging from 3 to 72 hours. After the immersion period, the plates were withdrawn and held above the molten salt for a $25 \mathrm{~min}$. period, reducing the possibility of thermal stresses affecting the desired stress profiles or influencing the 'native' flaw population. Subsequent to the ion exchange treatment, the glass slides were cleaned in deionized water and stored under vacuum.

A number of normal, non-strengthened glass slides and chemically strengthened glass slides, 10 specimens per ion exchange time and 10 specimens of normal, non-strengthened glass slides, were tested to measure the strength increase produced by ion-exchange using a four point bend apparatus. The four point flexural strength measurements were performed on a cross-head driven mechanical test machine under displacement control (Model 1132, Instron Systems, Canton, MA), with inner and outer spans spans of $13.05 \mathrm{~mm}$ and $30.2 \mathrm{~mm}$ respectively, per ASTM standard. ${ }^{14}$ The tests were performed under atmospheric conditions with relative humidity at approximately $20 \%$ and at a stress rate of $1.2 \mathrm{MPa} / \mathrm{sec}$. The stress at failure was calculated using the ion exchanged glass slide dimensions and loading span dimensions in conjunction with the failure load and the four point bend formulae

$$
\sigma_{F}=\frac{3 P_{F}\left(s_{O}-s_{I}\right)}{2 b d^{2}}
$$

where $P_{F}$ is the failure load, $s_{0}$ and $s_{I}$ are the outer and inner span lengths, $b$ is the specimen width and $d$ is the specimen height. Ion exchanged and non-ion exchanged glass slides were also indented on one surface using a Vickers hardness indenter (Zwick 3212) at loads of between $0.25 \mathrm{~kg}$ and $5 \mathrm{~kg}$; their flexural strength was then measured as a function of the different indentation crack sizes, measured with an optical microscope (Model Eclipse ME600P, Nikon, Japan).

The residual stress developed during ion exchange was measured in single ion exchanged glass slides by the wafer curvature method. ${ }^{15,16}$ In order to use this technique, two glass slides were weakly bonded together (described below) before the ion exchange. Hence, when the bilayer plate was separated using a razor blade (described below), each glass plate exhibited a measurable curvature because only one surface was subjected to ion exchange. Careful attention was paid to using only bilayers that were weakly bonded and that could be debonded along their pre-existing interface. The ion-exchanged edges of the glass plates were also removed by diamond grinding to minimize non-planar stresses that could influence the curvature. Successive layers of the ion exchanged surface were removed using buffered hydrofluoric acid $\left(1: 10 \mathrm{HF}: \mathrm{H}_{2} \mathrm{O}\right)$. To prevent material removal from the non-ion exchanged side 
of the glass plate, the non-ion exchanged side was coated with photoresist (Shipley 812, Shipley Corporation) by spin coating. The photoresist was removed with acetone after etching, so as not to affect the curvature. Experiments were performed to determine the etching rate of the soda lime silicate glass. The depth of material removed from the surface was determined by masking an area with photoresist, and measuring the etch depth with a profilometer vs etching time.

After etching of the ion exchanged area for a given time period, the curvature of the plate was measured (Tencor FLX 2320 Curvature Measurement Tool). The changing curvature $\kappa(h)$ can be related to the residual stress $\sigma(\mathrm{h})$ through a modified version of Stoney's equation ${ }^{17}$

$$
\sigma(h)=\frac{2}{3} M_{S} h \kappa(h)+\frac{1}{6} M_{S} h^{2} \kappa^{\prime}(h)+\frac{1}{3} M_{S} \int_{0}^{h} \kappa(z) d z,
$$

where $\mathrm{M}_{\mathrm{S}}$ is the biaxial modulus given as $M_{S}=\frac{E_{S}}{\left(1-v_{S}\right)}, \kappa^{\prime}(\mathrm{h})$ is the derivative of the curvature, $\mathrm{z}$ is distance from the centroid and $\mathrm{h}$ is the mean incremental etch depth from the exchanged surface. Three specimens at each ion exchange temperature and time were measured to determine the residual stress profile.

\section{(2) Laminate Fabrication and Characterization}

Ion exchanged glass plates were used in the wafer direct bonding process to create either 3 or 5 layer laminates with external dimensions of either $50 \times 25 \times 3 \mathrm{~mm}$ or $50 \times 25 \times 5 \mathrm{~mm}$. Direct wafer bonding was accomplished in both air, without particulate control and deionized water, similar to that reported by Parkes et.al. ${ }^{18}$ The procedure for bonding the plates together after the ion exchange in deionized water included the following steps: sonicate in acetone for $3 \mathrm{~min}$, further sonicate in deionized water for $3 \mathrm{~min}$, cleaning/etching in $\mathrm{NH}_{4} \mathrm{OH} / \mathrm{H}_{2} \mathrm{O}_{2} / \mathrm{H}_{2} \mathrm{O}(1: 1: 6)$ at $80{ }^{\circ} \mathrm{C}$ for $20 \mathrm{~min}$., water rinse, plate contact under water, blow dry with nitrogen gas. The procedure for bonding the plates together after ion exchange in air included all of the above steps except that the plates were contacted in air after a blow dry with nitrogen gas. The mated plates were then transferred to a vacuum $\left(6 \times 10^{-4}\right.$ torr) furnace (Centour Model No. 60-6X8-W-M04S4-A-16) within the frame of a hot-press for bonding at temperatures ranging between 200 and $400^{\circ} \mathrm{C}$, for periods between $15 \mathrm{~min}$ and $24 \mathrm{hrs}$ under a constant pressure of $2.5 \mathrm{MPa}$.

The bonded laminates were examined and rejected if they contained observable interfacial flaws under an optical microscope (Model Eclipse ME600P, Nikon, Japan). The laminated specimens were diamond cut into bars with dimensions of $50 \times 3 \times 3 \mathrm{~mm}$. The lateral surfaces of the laminar bar specimens were then ground and polished to produce parallel, polished surfaces.

To test the effectiveness of the wafer direct bonding process, non-ion exchanged glass plates and ion exchanged glass plates were bonded, using the procedure outlined above, to form two-layer laminates. The "strength" of the bond was measured by measuring the critical strain energy release rate for the bonded interface using the double cantilever beam test configuration. As detailed by Maszara et. al., ${ }^{19}$ a razor blade with thickness $2 h_{b}$ was pushed into the interface between the two glass plates, each of thickness $t$, to create a stable crack of length, $L$. The length of the stable crack produced by the wedge was measured in a light microscope. As shown by Lawn ${ }^{2}$ the critical strain energy release rate, $G_{1 c}$, can be determined with 


$$
G_{I C}=2 \gamma=\frac{3 E h^{2} t^{3}}{4 L^{4}}
$$

where $E$ is Young's modulus, $t$ is the glass layer thickness, $L$ is the stable crack length and $h$ is half the razor blade thickness. In early efforts to determine the $G_{c}$ of the interface, the bonded interface exhibited significant crack growth for between 15 to 30 seconds. To reduce the possible effects of this crack growth on the $G_{c}$ measurement, the crack length was measured 1 min after a $1 \mathrm{~mm}$ incremental insertion of the blade, which allowed enough time for elastic equilibrium and crack stabilization. ${ }^{20}$ The blade insertion increments of $1 \mathrm{~mm}$ provided a statistically relevant average value free from factors such as non-uniform surface roughness, composition and contamination.

The strength of each laminar bar, including laminates fabricated without an ion exchange to serve as monolithic test specimens, was determined by measuring the flexural strength of specimens containing a pre-existing crack introduced with a Vickers indenter. One lateral surface (surface perpendicular to the layer orientation) was ground and polished to a mirror finish to allow correct placement of a small Vickers indentation. Indent loads between 0.25 to $5 \mathrm{~kg}$ were placed in the middle of the center layer and the resulting crack sizes were measured with an optical microscope (Model Eclipse ME600P, Nikon, Japan). Four point flexural strength measurements were performed on a cross-head driven mechanical test machine under displacement control (Model 1132, Instron Systems, Canton, MA), with inner and outer spans spans of $13.05 \mathrm{~mm}$ and $30.2 \mathrm{~mm}$ respectively, at a stress rate of $1.2 \mathrm{MPa} / \mathrm{sec}$. Ten laminate specimens, ion exchanged and hot press bonded for the same temperatures and times, were tested for each indentation load. The stress at failure was calculated using the laminate bar dimensions and loading span dimensions in conjunction with the failure load and the four point bend formulae found in equation 1.

Indirect observations of the extending crack were made using cellulose acetate strips applied during loading. ${ }^{5,6}$ The cellulose strip was carefully placed on the tensile face of the specimen after the application of acetone during which the loading rate was paused. The cellulose strips were removed after 1 minute and placed on a glass slide containing double-sided tape before optical images were taken using a Nomarski (Differential Interference Contrast) setup.

\section{Results}

\section{(1) Single Glass Sheet Strength Results}

Failure strengths of glass sheets ion exchanged at temperatures between 350 and $450{ }^{\circ} \mathrm{C}$ and for times between 3 and 72 hrs are shown in Figures 1 and 2. Results for specimens that did not contain a Vickers indentation crack are shown in Figure 1. The standard deviation is shown to be either within the dimensions of the data point or by the error bars. As shown, the strength of the single ion exchanged glass sheets increased with increasing ion exchange time and increasing ion exchange temperature. The strengths for any of the ion exchanged specimens were considerably higher relative to the non-ion exchanged specimens, which was determined to be 71 $\mathrm{MPa}$. It is also clear from Figure 1. that the strength reached a plateau value after approximately $24 \mathrm{hrs}$. For every exchange period, the strength exhibited a relatively large variability as shown 
by the extended brackets associated with each data point. An analysis of the fracture behavior supports the observation of high strength variability. Despite the employment of beveled edges on all specimens for single layer tests, fractography revealed that a number of specimens failed at the edges of the glass plate rather than within the center region of the specimen. Generally those exhibiting tortuous fracture paths from edges and corners also exhibited higher strengths than specimens exhibiting flatter fracture surfaces. A common observation for all ion exchanged specimens was the larger number of shards produced during fracture. In comparison, the non-ion exchanged specimens exhibited similar fracture paths but a smaller number of larger fragments.

\section{Insert Figure 1.}

The results from the introduction of artificial flaws with a Zwick Vickers indenter are reported in Figure. 2. Since it is well know that crack introduction from an indenter will increase in size as the load is increased, the strength of the ion exchanged, single glass plates decreased with increasing indent load, a trend similar to the flaw size-strength relation predicted with the Griffith equation. Fractography for artificial flaws at small indent loads showed similar results as the specimens fractured without the introduction of surface compressive stress, with high strength variability resulting from the differences in tortuous and simple crack paths. Increased indent loads reduced the strength variability, as the artificial flaw became the dominant failure mechanism in all specimens.

\section{Insert Figure 2.}

\section{Residual Stress Profiles}

The residual stress profiles of ion exchanged single glass sheets are shown in Figs. 3 and 4. Although each data point represents the average value of stress for the portion of material etched away, the results are shown as points. Increased accuracy in the residual stress profiles can be achieved by reducing the depth of material removal, as shown in both figures for stress determinations closer to the surface. In all processing conditions the maximum compressive stress was located below the surface apparently due to the viscoelastic relaxation behavior at the high processing temperatures and times. The maximum compressive stress decreased for exchange conditions at the higher temperature $\left(450^{\circ} \mathrm{C}\right)$ and longer periods $(24 \mathrm{hr})$ as compared to the results from the lower processing temperature $\left(350^{\circ} \mathrm{C}\right)$ and period $(12 \mathrm{hr})$. As expected the depth of exchange was significantly smaller for exchange at $350^{\circ} \mathrm{C}$ and the gradient of the stress profile, considerably greater.

\section{Insert Figure 3.}

\section{Insert Figure 4.}

Figure 5 shows the stress profiles of the same ion exchanged single glass sheets after a heat treatment, which is expected to relax the compressive stress when the ion-exchanged glass sheets are bonded to form laminates. The heat treatment schedule was exactly the same used during wafer direct bonding. The same furnace was used for these heat treatments as used for the vacuum hot-pressing that was used to bond the sheets into laminates. 


\section{Insert Figure 5.}

As shown in Fig. 5, the stress profiles produced by the heat treatment more closely resemble a step profile, with the gradient considerably flatter than produced by ion-exchange alone as shown in Figures 3 and 4 . In addition to the change in stress profile, the maximum residual compressive stress, still situated approximately $1 \mu \mathrm{m}$ below the surface, decreased from $328 \mathrm{MPa}$ to $237 \mathrm{MPa}$ for an ion exchange at $450^{\circ} \mathrm{C}$ for $12 \mathrm{hr}$ and a heat treatment at $250^{\circ} \mathrm{C}$ for $24 \mathrm{hr}$. Likewise, the maximum compressive stress for an ion exchange at $450{ }^{\circ} \mathrm{C} / 24 \mathrm{hr}$ decreased from $288 \mathrm{MPa}$ to $193 \mathrm{MPa}$ after an heat treatment at $300^{\circ} \mathrm{C} / 24 \mathrm{hr}$.

\section{Wafer Direct Bonding}

Bonding glass slides under water provided significantly better results than bonding glass slides in air. An optical microscopic examination of the glass surface showed that the flow of DI water would remove particulate contamination. Particle contamination was a significant factor in what appeared to be a poor bond. A comparison of the critical strain energy release rate for 2layer laminates bonded in air and water showed only small variations, and less than expected from imperfections observed at the bonded interface for air bonded specimens. The detrimental effects of air bonding became apparent after 2-layer laminate bars were produced by diamond grinding; the air bonded laminates showing a significant tendency towards sub-critical crack growth, which initiated from interfacial flaws situated close to the edges. Bonding glass under water exhibited fewer problems; however, vapor bubbles did become trapped between the sheets during bonding. Additionally the glass slides used were float glass and as such, exhibited variations in surface roughness, which was a significant factor in the quality of the bond. ${ }^{11}$ The surface roughness of a random selection of glass slides was measured using an Atomic Force Microscope. The results showed that the surface roughness of the glass slides varied between 0.7 and $25 \mathrm{~nm}$. For the largest value of surface roughness $(25 \mathrm{~nm})$, wafer direct bonding is extremely difficult to achieve without producing interface flaws. On the other hand, for the typical value of surface roughness in the range of 0.5 to $1 \mathrm{~nm}$, the bond appeared to be good, judging from interfacial defects observed by optical observations. ${ }^{11}$ The application of pressure during hot pressing, which apparently allowed asperities to flatten, increased the quality of the bond. Although interfacial flaws were unwanted, they did not appear critical to the mechanical measurements reported below.

\section{Critical Strain Energy Release Rate of Bonded Interface}

Bonded laminates consisting of only two sheets and one interface were produced to identify the effects of bonding conditions, temperature and time, as well as the effect of the ion exchange itself, on bond quality. The results shown in Fig. 6 indicate that $G_{c}$ increases with both hot pressing time and temperature. The introduction of a residual compressive stress appeared to slightly lower the value critical strain energy release rate.

\section{Insert Figure 6.}


The results shown in Fig. 6 identified conditions to optimize the bond strength for producing the laminates used for threshold strength determinations. With careful consideration given to the effect of bonding temperature on the unwanted diffusion of $\mathrm{K}^{+}$ions that would reduce the residual compression, the temperature and time of the wafer direct bonding process was chosen to be $250^{\circ} \mathrm{C}$ for 12 to $24 \mathrm{hr}$.

\section{(5) Glass Laminate Strength Results}

Figure 7 reports the strength data for the laminates, each laminate consisting of 3 layers that were produced at various exchange temperatures, exchange periods, as well as direct wafer bonding temperatures and times. This data shows that the failure stress of the laminates was relatively independent of the initial flaw size, suggesting that the failure stress is the threshold strength. As expected, the strength of the monolithic glass without compressive layers was strongly dependent on the size of the indention cracks. The value of the threshold strength was highest, namely, $112 \mathrm{MPa}$, for the laminates exchanged at $350^{\circ} \mathrm{C}$ for $24 \mathrm{hr}$. The standard deviation, shown by the data points themselves, was less than $5 \%$ of the respective laminate strength.

\section{Insert Figure 7.}

A comparison of the results for glass laminates (Figure 7.) and single ion exchanged sheets (Figure 2.), indented and tested in the 4 point bend apparatus show that the glass laminates become an effective alternative to single sheets at indent loads greater than $3 \mathrm{~kg}$ or crack sizes greater than $195 \mu \mathrm{m}$. Studies into the possibility of further increasing the strength of the glass laminates by increasing ion exchange times past $48 \mathrm{hrs}$ found that the diamond cut, ground and polished test specimens succumbed to sub critical crack growth emanating from the interface intersecting the polished surface. The structural stability of the glass laminates did not last long enough to allow mechanical testing. Attempts to isolate the laminates under a vacuum slowed the sub critical crack growth but did not prevent failure upon re-introduction to the normal atmosphere.

Indirect observations of the extending crack were made using a cellulose acetate replicating technique during loading. As large closure stresses act upon the crack surfaces with unloading, application of cellulose acetate strips to specimens held at different loads produced replicas of the extending crack at different loads. The cellulose acetate strips were placed on the tensile face subsequent to the application of acetone, which softened the cellulose strips. The softened strips were drawn into the crack by capillarity while the acetone evaporated before being removed from the tensile face and mounted onto a glass slide for observation under an optical microscope. As detailed in Fig. 9(a), the replicas showed that the crack extended in several increments during loading. In one increment, the crack extended to (or into) the thin compressive layer. In the last increment, the crack extended to the interface between the two bonded glass sheets. At this location, as shown in Fig. 9(b) a crack, perpendicular to the extending crack, was also observed on the plane where the two glass sheets were bonded together.

\section{Insert Figure 8.}


The fracture surface for a laminate, ion exchanged at $350^{\circ} \mathrm{C}$ for $24 \mathrm{hr}$ and bonded at 250 ${ }^{\circ} \mathrm{C}$ for $12 \mathrm{hr}$ is shown in Figure 9. Fractography of glass fracture surface, illustrated in Figure 9(a)., is aided by markings on the surface that clearly define the progressive location and shape of an extending crack. These markings are caused by slight changes in crack path due to vibrations induced by fracture. Figure 9 shows that after the indentation pre-crack extends across the surface of the central, thick layer and stops at the compressive interfacial region, it also extends deep within the layer to approach the neutral axis of the flexural bar specimen. This observation is identical to those found for ceramic laminates that exhibit a threshold strength. ${ }^{5,6}$

In Figure 9, examination of the layers adjacent to the central layer show numerous reinitiation points along the interface between central and adjacent layers. This fracture surface differs significantly from fracture surfaces at shorter ion exchange periods where striations near the corners of the tensile face suggest one dominant flaw near the interface causing catastrophic fracture. At ion exchange times of $24-48 \mathrm{hrs}$, the regions adjacent to the interface in the outer layers exhibit multiple flaws/re-initiation points across a large section of the specimen height, from the corners at the tensile face to close to the specimen centre. These re-initiation points propagate along the interface, coalescing and leading to catastrophic failure.

\section{Insert Figure 9.}

In ion exchanged glass laminates, crack re-initiation into the second thick layer is precluded by crack propagation down the interface between two glass wafers, causing a step in the fracture surface on either side of the central thick layer. This fracture behavior is very different from that found when testing monolithic laminates, in which the crack extends completely across the test specimen without a change in crack direction at the interface between central and outer layers. Comparisons between the two crack paths show that crack deflection at the interface is highly dependent on the residual compressive stress located in regions adjacent to the interface.

\section{Discussion}

\section{(1) Ion Exchanged Glass}

The results for the strength of single sheets of ion exchanged glass correlate well with previous investigations. Of greatest concern in the application of ion exchange to glass is the large standard deviations in the strength. As described in the introduction and born out by Figures 3,4 and 5, the residual stress profiles of ion exchanged glass are not step functions, but show a gradual decrease with increasing depth. Hence, due to the statistical nature of the flaw population, the possibility of the residual stress embedding all surface flaws is small. The standard deviations only become manageable with the introduction of large artificial flaws that dominate the native flaw population. As these artificial flaws extend well past the range of the residual stresses created by the ion exchange, failure can be predicted more accurately.

(2) Residual Stress Profiles 
The measurement of the residual stress profiles created from the ion exchange process illustrates the difficulty of creating a thick layer of residual, compressive stress at the surface of the soda lime silicate glass. Previous investigations into threshold strengths of alumina/aluminamullite and alumina/tetragonal-to-monoclinic zirconia laminates have been able produce residual compressive stresses of magnitude $350 \mathrm{MPa}$ with tensile/compressive layer thickness ratio of $10: 1$ and $560 \mathrm{MPa}$ with tensile/compressive layer thickness ratio of $11: 1$, respectively. ${ }^{5-7}$ In comparison, ion exchange of Soda Lime Silicate glass for $24 \mathrm{hrs}$ at $350{ }^{\circ} \mathrm{C}$ gives a residual compressive stress of $331 \mathrm{MPa}$ within a relatively thin layer, approximately 2 to $3 \mu \mathrm{m}$, just below the surface. With the residual compressive stress decreasing rapidly to zero in approximately $20 \mu \mathrm{m}$ from the surface, the effective tensile/compressive layer thickness ratio for these glass laminate is approximately 100:1.

As illustrated in Fig. 6, the stress profile is changed with the heat treatment required for wafer direct bonding. While the residual stress profile becomes more similar to a step function, the magnitude is reduced from $288 \mathrm{MPa}$ to $193 \mathrm{MPa}$ for an ion exchange treatment of $24 \mathrm{hr}$ at $450{ }^{\circ} \mathrm{C}$ and heat treatment of $24 \mathrm{hr}$ at $300^{\circ} \mathrm{C}$. Hence, there is an apparent trade-off between maintaining the highest residual compressive stress and increasing the bond 'strength' of the glass laminates.

\section{(3) Threshold Strengths in Glass Laminates}

The results from Fig. 7 show that the strength of glass laminates that contain the compressive regions between the laminates is insensitive to the size of the surface flaws introduced by indentation, i.e., the laminates exhibit a threshold strength. The threshold strength increases with increasing exchange time and decreases slightly with increasing exchange temperature due to the trade-off between a decreased magnitude of residual compressive stress and increasing depth of the stress from the exchange surface. It appeared that the threshold strength could be further increased with increasing exchange time period, however, the difficulty of maintaining structurally stable laminates at exchange periods of more than $48 \mathrm{hrs}$ precluded further studies of this effect.

Of significant interest is the change in the crack path as it extends across the interface. In previous studies of ceramic laminates via co-densification of alternating thick and thin layers of different powder materials, large cracks stopped as they entered the compressive layers as they were observed in the current study. For previous studies of ceramic laminates, the cracks either extended straight though or bifurcated as a branched crack though the compressive layer. It was found that bifurcation, a new type of steady state crack extension, is only observed for conditions of either high compressive stress or thick compressive layers. ${ }^{5 \cdot 7}$ Relative to the ceramic laminates, the compressive stresses within the glass laminates are neither large nor are the compressive regions thick. Because the compressive stresses are relatively small and the compressive layer relatively thin, based on previous studies of ceramic laminates, one would expect the crack in the glass laminates to extend straight though the compressive region with increasing applied tension, and then to cause catastrophic fracture. Instead, the cracks were observed to extend through only the initial portion of the compressive region before stopping close to the interface. And, before catastrophic fracture, the cracks extended along the bonding surface for a short distance as shown in Fig. 9(b). Since cracks in the glass laminates produccd from plates without compressive layers (not ion exchanged) extended straight across the 
interface during catastrophic fracture, it appears that the extension along the interface was a result of the compressive stresses in these regions.

The effect of crack deflection along an interface has been explored previously by Hutchinson and $\mathrm{He}^{21}$ where they showed that crack deflection at the interface for materials exhibiting no residual stress fields requires interfacial toughness ratios $\left(\Gamma_{\mathrm{i}} / \Gamma_{\mathrm{s}}\right)$ of less than 0.26 . Using a toughness value for SLS Glass of $2 \mathrm{~J}_{\mathrm{J}} \mathrm{m}^{-2},{ }^{2}$ and the values measured in double cantilever beam tests $\left(1.3 \mathrm{~J} . \mathrm{m}^{-2}\right.$ for the interface under bonding conditions of $250^{\circ} \mathrm{C}$ for $\left.24 \mathrm{hrs}\right)$ produces a $\Gamma_{\mathrm{i}} / \Gamma_{\mathrm{s}}=0.65$. Since this ratio is significantly larger than the condition for crack deflection described by Hutchinson and He, one would expect the crack to go straight though the interface.

In a later paper, $\mathrm{He}$, Evans and Hutchinson ${ }^{22}$ showed that when the interface is subject to a residual compressive stress, the toughness ratio required for a crack to deflect along the interface can be much larger than 0.26 and depends on the magnitude of the compressive stress. Hence, the addition of compressive stress fields at the interface increases the probability of crack deflection along the interface. Assuming a toughness ratio of $\Gamma_{i} / \Gamma_{s}=0.4-0.5$, calculated by taking a value for the interfacial toughness from Figure 6., representative of both the ion exchange temperature and time as well as the hot press temperature and time for the laminates tested under four point bend conditions (approximately 0.8 to $1 \mathrm{Jm}^{-2}$ ) and dividing by the toughness of bulk glass (approximately $2 \mathrm{Jm}^{-2}$ ), $\mathrm{K}_{\mathrm{lC}}=0.8 \mathrm{MPa} \cdot \mathrm{m}^{-1 / 2}, \sigma_{\mathrm{c}}=180-230 \mathrm{MPa}$ (compressive stress directly adjacent to interface) and an interfacial flaw of approximately $1 \mu \mathrm{m}$ (laminates examined under the optical microscope containing interfacial flaws larger than $1 \mu \mathrm{m}$ were rejected before undergoing any strength tests), the analytical model provided by He, Evans and Hutchinson suggests that cracks extending to the interface will be deflected along the interface consistent with the phenomenon reported above.

\section{Conclusion}

Glass laminates produced through ion exchange and wafer direct bonding have been shown to exhibit a threshold strength during mechanical tests with the introduction of artificial flaws. The maximum threshold strengths are larger than the strength of an un-indented single glass sheet under flexure and become an effective alternative to single ion exchanged sheets with increasing artificial flaw size or indent load. Using cellulose acetate replicas the cracks were observed to stop propagating close to the interface within the region of residual compressive stress. The wafer direct bonding process has been effective in creating glass laminates but produces weak interfaces due to the restriction on hot pressing temperature, promoting crack deflection along the interface during fracture.

\section{References}

1. Weibull W., "A Statistical Distribution Function of Wide Applicability," J. Appl. Mech., $18293(1951)$

2. Lawn B.R., Fracture of Brittle Solids, $2^{\text {nd }}$ Ed., Cambridge University Press, Cambridge, UK, 1993

3. Green D.J., Introduction to Mechanical Properties of Ceramics, Cambridge University Press, Cambridge, UK, 1998 
4. Hbaieb K., McMeeking R.M., "Threshold strength predictions for laminar ceramics with cracks that grow straight" Mech. Mater. 34755 -772 (2002)

5. Rao M.P., Rodel J., Lange F.F., "Residual Stress Induced R-curves in Laminar Ceramics that Exhibit a Threshold Strength," J. Am. Ceram. Soc., 84 [11] 2722-2724 (2001)

${ }^{6}$ Rao M.P., Lange F.F., "Factors Affecting Threshold Strength in Laminar Ceramics containing Thin Compressive Layers," J. Am. Ceram. Soc., 85 [5] 1222-1228 (2002)

7. Pontin M.G., Rao M.P., Sanchez-Herencia A.J., Lange F.F., "Laminar Ceramics Utilizing Zirconia Tetragonal-to-Monoclinic Phase Transformation to Obtain Threshold Strength," J.

Am. Ceram. Soc., 85 [12] 3041-3048 (2002)

8. Green D.J., Tandon R., Sglavo V.M., "Crack Arrest and Multiple Cracking in Glass

Through the Use of Designed Residual Stress Profiles," Science, 283 [5406] 1295-1297

(1999)

9. Satoh A., "Water Glass Bonding," Sen. Act. A, 72 160-168 (1999)

10. Wallis G., Pomerantz D.I., "Field Assisted Glass-Metal Sealing," J. Appl. Phys., 403946 (1969)

11. Plőßl A., Kräuter G., "Wafer Direct Bonding: Tailoring Adhesion between Brittle

Materials," Mater. Sci. Eng., R25 1-88 (1999)

12. Tong Q.-Y., Gösele U., Semiconductor Wafer Bonding: Science and Technology, John

Wiley and Sons, New York, USA, 1999

13. Pigeon F., Biasse B., Zussy M., "Low Temperature Pyrex glass Wafer Direct Bonding,"

Electron. Lett., 31 [10] 792-793 (1995)

14. ASTM C 158-95, "Standard Test Methods for Strength of Glass by Flexure,"

15. Flinn P.A., Gardner D.A., Nix W.D., "Measurement and Interpretation of Stress in

Aluminium Based Metallisation as a Function of Thermal History," IEEE Trans. Electron

Devices, ED43, 689-699, 1987

16. Schull A.L., Spaepen F., "Measurements of Stress during Vapor Deposition of Copper and

Silver Thin Films and Multilayers," J. Appl. Phys., 80 6243-6256 (1996)

${ }^{17 .}$ Freund L.B., "Some Elementary Connections between Curvature and Mismatch Strain in

Compositionally Graded Thin Films," J. Mech. Phys. Solids, 44 [5] 723-736 (1996)

18. Parkes C., Murray E., Gamble H.S., Armstrong B.M., Mitchell S.J.N., Armstrong G.A., "Characterization of Electronic Devices Employing Silicon Bonding Technology,"

Proceedings of the $1^{\text {st }}$ International Symposium on Semiconductor Wafer Bonding: Science, Technology and Applications, Vol. 92-7, The Electrochemical Society, Pennington, NJ, p321, 1992

19. Maszara W.P., Goetz G., Caviglia A., McKitterick J.B., "Bonding of silicon wafers for silicon-on-insulator," J. Appl. Phys., 64 [10] 4943-4950 (1988)

20. Tong Q.-Y., Gafiteanu R., Gösele U., "Water Enhanced Debonding of Room Temperature Bonded Silicon Wafers for Surface Protection Applications," Jpn J. Appl. Phys., 31 34833488 (1992)

${ }^{21 .}$ He M.Y., Hutchinson J.W., "Crack Deflection at an Interface between Dissimilar Elastic Materials," Int. J. Solids Struct., 25 [9] 1053-1067 (1989)

22. He M.Y., Evans A.G., Hutchinson J.W., "Crack Deflection at an Interface Between Dissimilar Elastic Materials: Role of Residual Stresses," Int. J. Solids Struct., 31 [24] 34433455 (1994)

VII. Figure Caption List 
Figure 1. Strength of ion exchanged single sheets as a function of exchange time.

Figure 2. Strengths of ion exchanged single sheets as a function of indent load.

Figure 3. Residual stress profile for single sheets ion exchanged at $350^{\circ} \mathrm{C}$.

Figure 4. Residual stress profile of single sheets ion exchanged at $450^{\circ} \mathrm{C}$.

Figure 5. Residual stress profile of ion exchanged single sheets at exchange temperature of 450

${ }^{\circ} \mathrm{C}$ and $24 \mathrm{hr}$, following an annealing heat treatment of $24 \mathrm{hr}$ for $250{ }^{\circ} \mathrm{C}$ and $300^{\circ} \mathrm{C}$.

Figure 6. Fracture surface energy of various ion exchanged and non-ion exchanged glass

laminates as a function of hot pressing temperature.

Figure 7. Flexural Strength Results for glass laminates, consisting of 3 layers exchanged at 350 and $450^{\circ} \mathrm{C}$ for 3 to $24 \mathrm{Hr}$. The monolithic laminates were produced using exactly the same bonding process without any ion exchanged regions. Included is an insert featuring a schematic diagram of the 4-point bend test geometry.

Figure 8 . The results from a cellulose acetate replica taken of the crack path for a glass laminate ion exchanged at $350^{\circ} \mathrm{C}$ for $12 \mathrm{hr}$, bonded at $250^{\circ} \mathrm{C}$ for $12 \mathrm{hr}$. Figure $8(a)$ shows the plot of crack length $(\mu \mathrm{m})$ against applied load (MPa) for the specimen. Figure 8(b) shows the crack (vertical line) close to the bond interface (horizontal line) at an applied load of $93 \mathrm{MPa}$.

Figure 9. Fracture Surface of glass laminate ion exchanged at $350^{\circ} \mathrm{C}$ for $24 \mathrm{hr}$, bonded at $250{ }^{\circ} \mathrm{C}$ for $12 \mathrm{hr}$. Figure 9(a) shows the entire fracture surface with the tensile face on top. The portion of interest is highlighted in Figures 9(b) and (c), showing the numerous re-initiation points in the outer layer, adjacent to the interface. Figure 9(c) illustrates the interactions between re-initiation points, with overlaps clearly evident. 


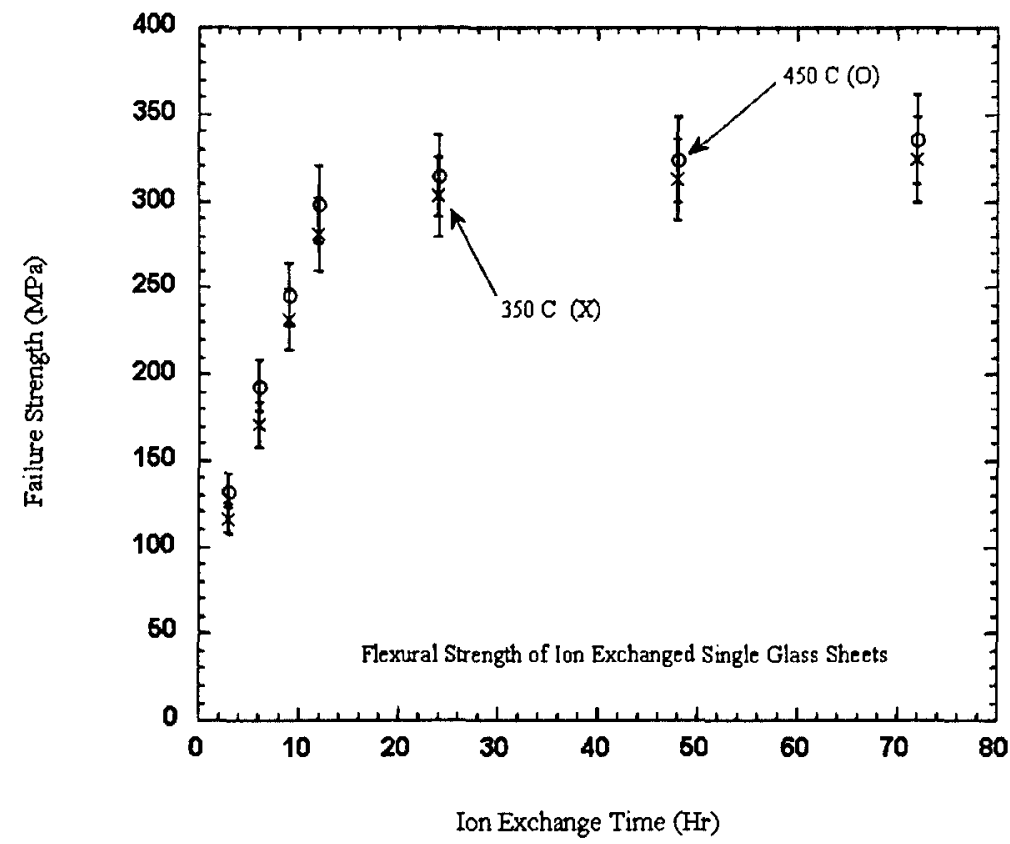

Figure 1. Strength of ion exchanged single sheets as a function of exchange time.

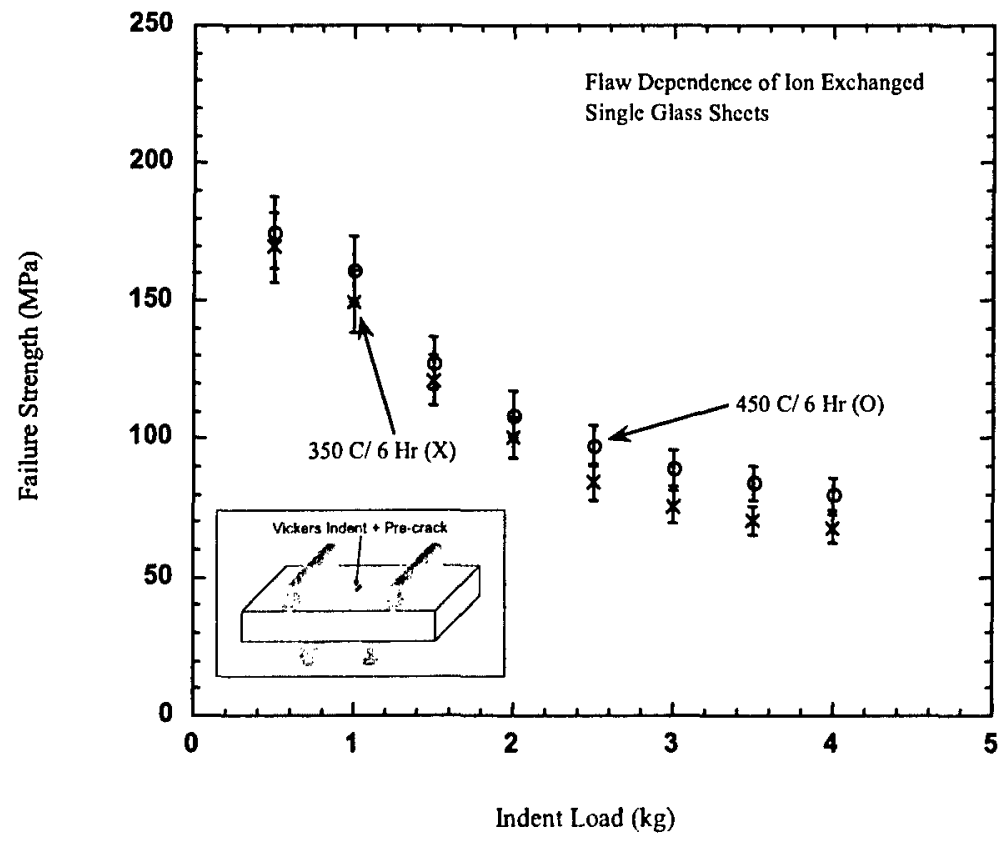

Figure 2. Strengths of ion exchanged single sheets as a function of indent load. Included is an insert featuring a schematic diagram of the 4-point bend test geometry. 


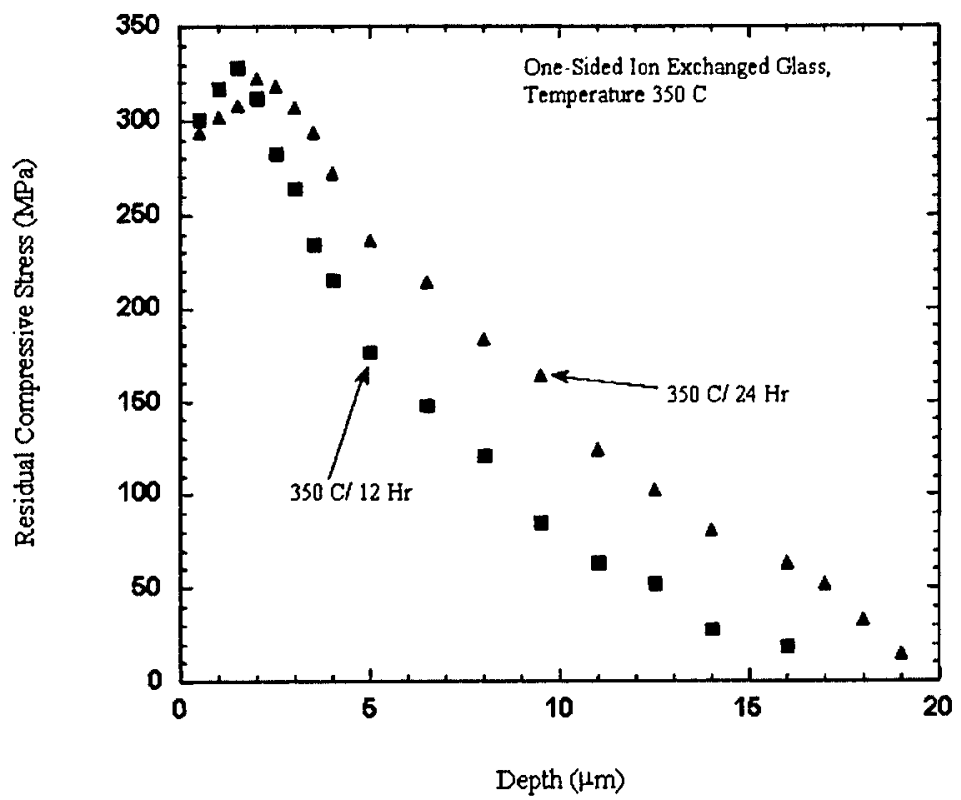

Figure 3. Residual stress profile for single sheets ion exchanged at $350^{\circ} \mathrm{C}$.

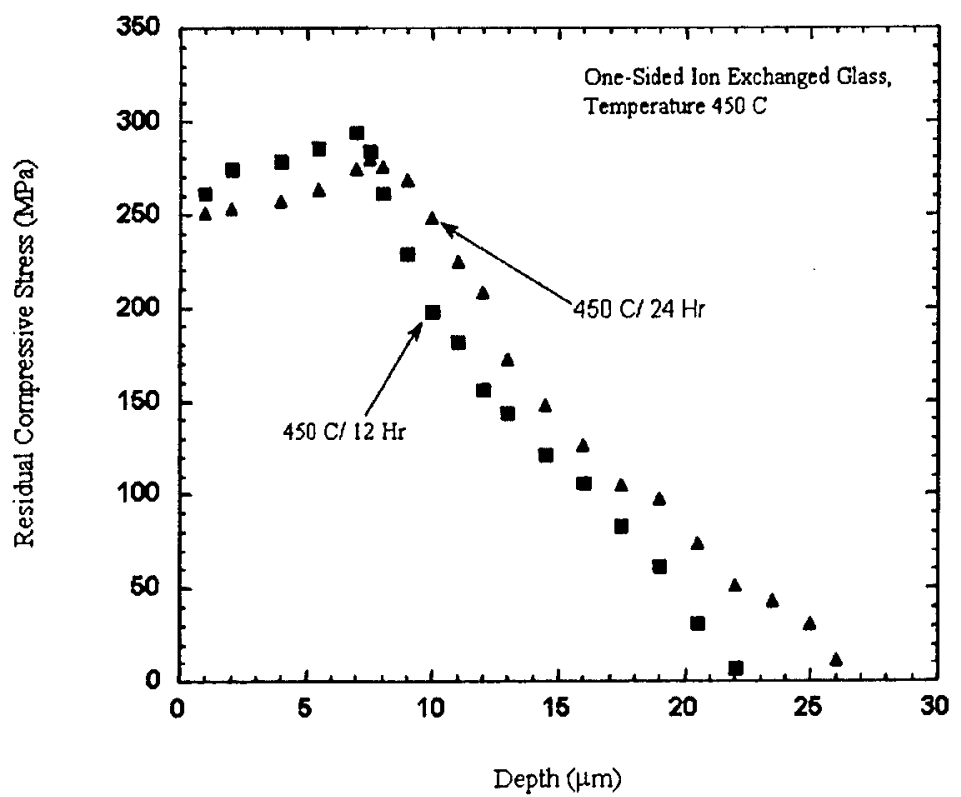


Figure 4. Residual stress profile of single sheets ion exchanged at $450{ }^{\circ} \mathrm{C}$.

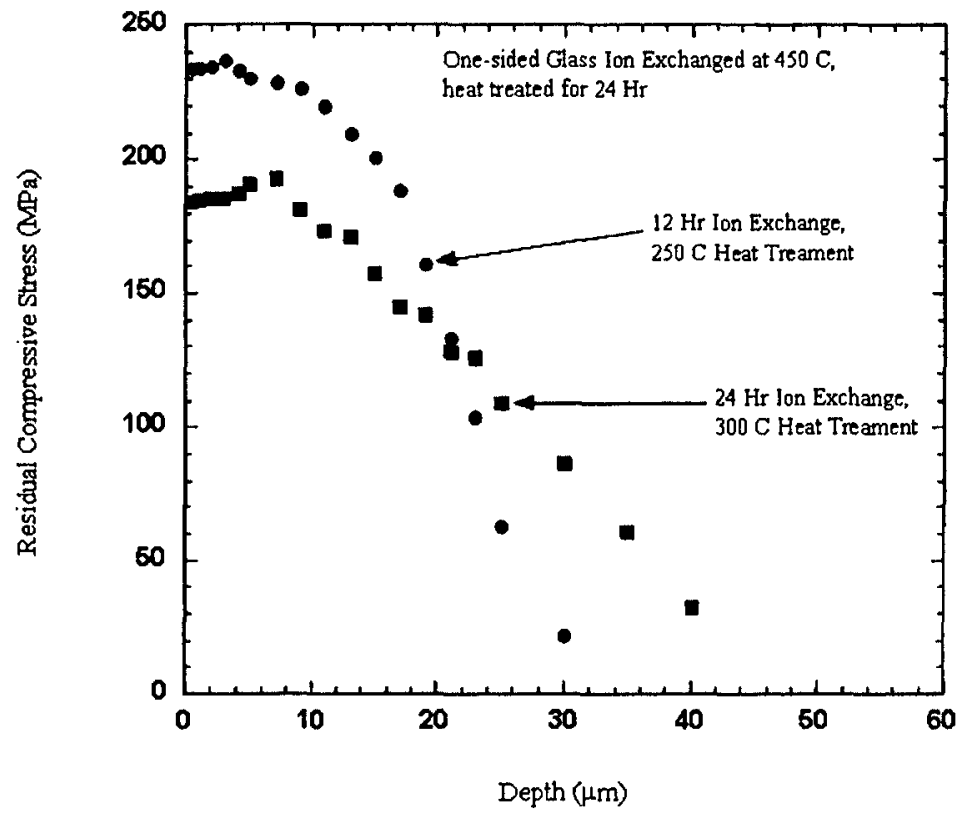

Figure 5. Residual stress profile of ion exchanged single sheets at exchange temperature of $450^{\circ} \mathrm{C}$ and $24 \mathrm{hr}$, following an annealing heat treatment of $24 \mathrm{hr}$ for $250{ }^{\circ} \mathrm{C}$ and 300 ${ }^{\circ} \mathrm{C}$. 


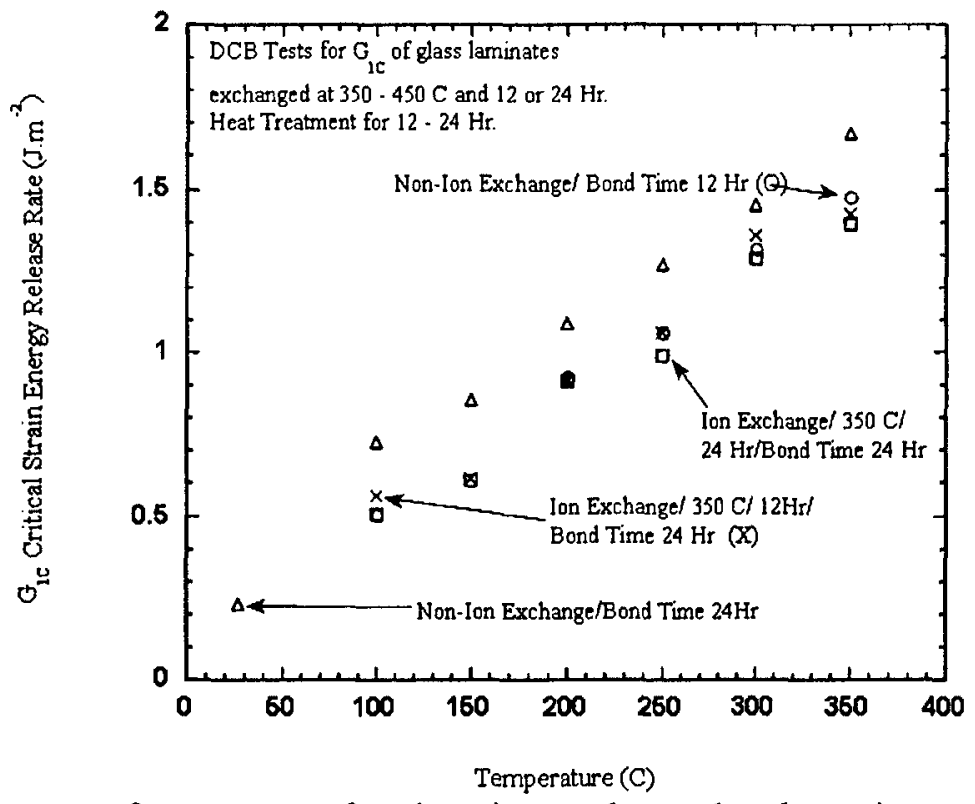

Figure 6. Fracture surface energy of various ion exchanged and non-ion exchanged glass laminates as a function of annealing temperature.

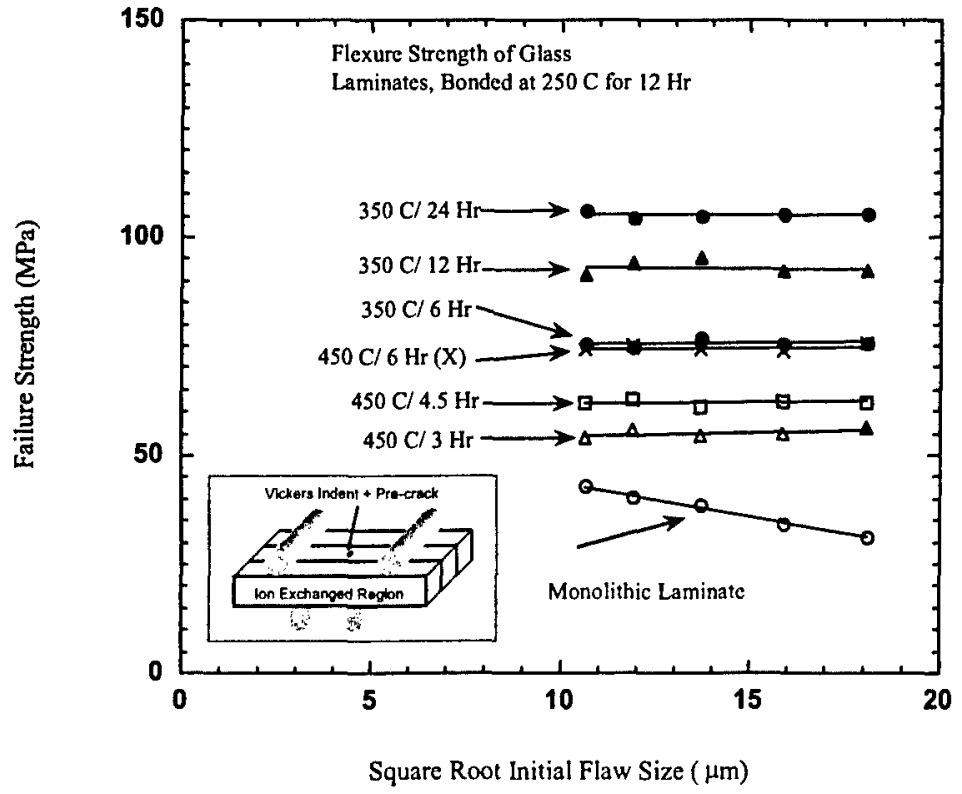

Figure 7. Flexural Strength Results for glass laminates, consisting of 3 layers exchanged at 350 and $450^{\circ} \mathrm{C}$ for 3 to $24 \mathrm{Hr}$. The monolithic laminates were produced using exactly the same bonding process without any ion exchanged regions. Included is an insert featuring a schematic diagram of the 4-point bend test geometry. 


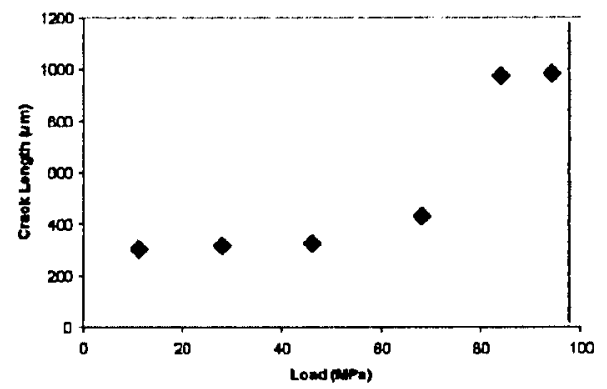

(a)

Figure 8. Cellulose acetate replica taken of the crack path for a glass laminate ion exchanged at $350^{\circ} \mathrm{C}$ for $9 \mathrm{hr}$, bonded at $250^{\circ} \mathrm{C}$ for $3 \mathrm{hr}$. Figure 8(a) shows the plot of crack length $(\mu \mathrm{m})$ against applied load $(\mathrm{MPa})$ for the specimen. Figure $8(\mathrm{~b})$ shows the crack (vertical line) close to the bond interface (horizontal line) at an applied load of 93 $\mathrm{MPa}$. 

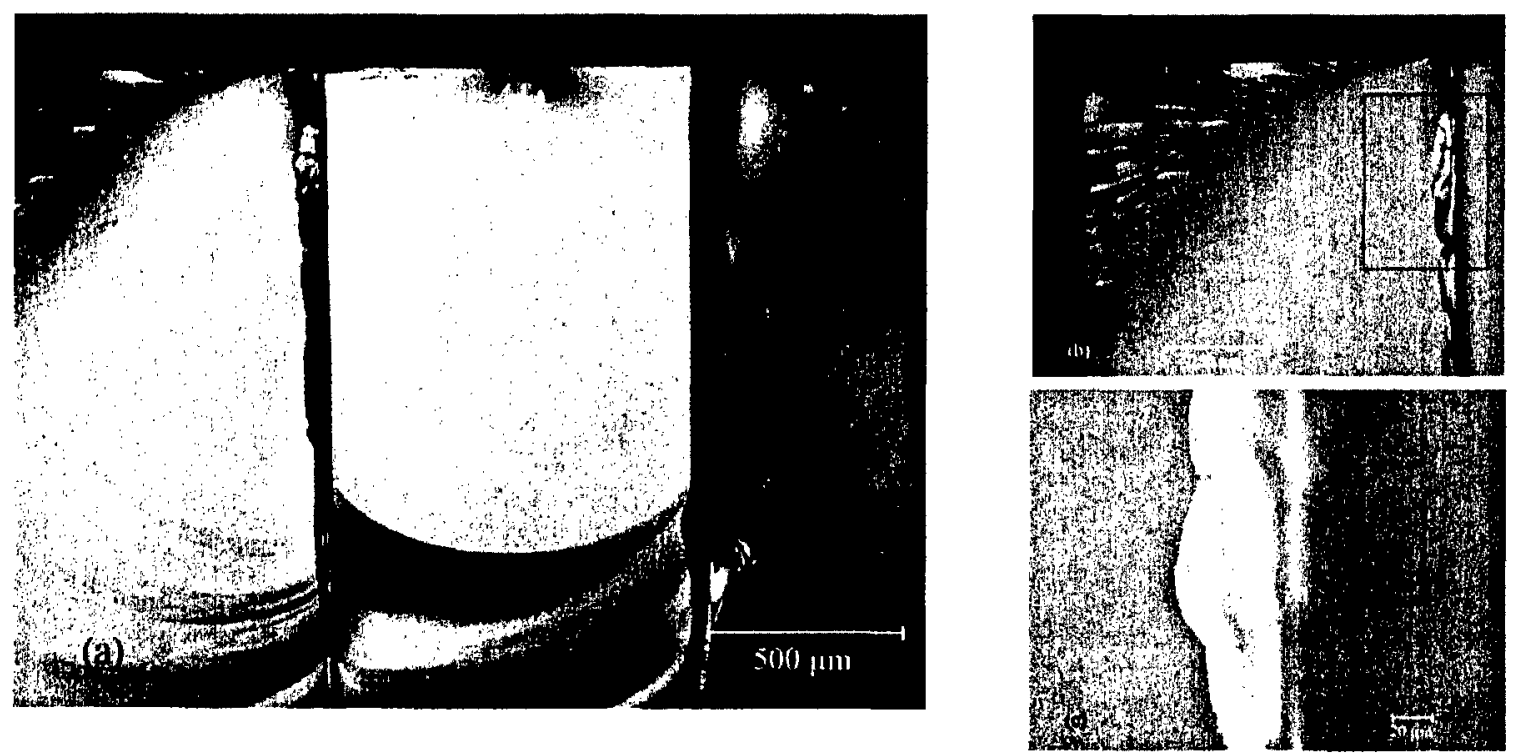

Figure 9. Fracture Surface of glass laminate ion exchanged at $350^{\circ} \mathrm{C}$ for $24 \mathrm{hr}$, bonded at $250{ }^{\circ} \mathrm{C}$ for $12 \mathrm{hr}$. Figure 9(a) shows the entire fracture surface with the tensile face on top. The portion of interest is highlighted in Figures 9(b) and (c), showing the numerous re-initiation points in the outer layer, adjacent to the interface. Figure 9(c) illustrates the interactions between re-initiation points, with overlaps clearly evident. 